\title{
TRANSFER JARI KEDUA JARI KAKI UNTUK REKONSTRUKSI JARI PERTAMA JARI TANGAN SETELAH TRAUMA LISTRIK (LAPORAN KASUS)
}

\author{
Agus Roy R.H. Hamid ${ }^{1 *}$, Sitti Rizaliyana ${ }^{1}$, M. Sjaifuddin Noer ${ }^{1}$, Gwendy Aniko ${ }^{2}$ \\ ${ }^{1}$ Program Studi Bedah Plastik dan Rekonstruksi, Fakultas Kedokteran Universitas Airlangga, RSUD Dr. Soetomo, \\ Surabaya, Indonesia.*Korespondensi: royruslyhamid@yahoo.com. \\ ${ }^{2}$ Departemen Bedah Plastik dan Rekonstruksi, Fakultas Kedokteran Universitas Indonesia, RSUPN Dr. Cipto \\ Mangunkusumo, Jakarta, Indonesia.
}

\begin{abstract}
ABSTRAK
Latar belakang: jari pertama memiliki peran yang sangat penting pada fungsi tangan. Rekonstruksi jari pertama jari tangan dapat dilakukan menggunakan jari pertama jari. Jari kedua jari kaki dapat digunakan apabila jari pertama jari kaki tidak dapat digunakan sebagai lokasi donor, misalnya, ketika tingkatan amputasi melebihi dari sepertiga proksimal metakarpal pertama dan diperlukan tulang metatarsal dengan panjang yang signifikan untuk menyediakan ukuran yang cukup pada rekonstruksi jari pertama tangan. Kasus: dilaporkan satu kasus, laki-laki, 24 tahun, datang ke Instalasi Gawat Darurat, Rumah Sakit Dr. Soetomo dengan hilangnya jari pertama jari tangan setelah trauma listrik. Pada pasien telah dilakukan debridemen dan flap lokal pada pergelangan tangan kiri dan skin graft pada tengan kanan. Flap viable dan hangat. Setelah hari ke-5 operasi, graft take 100\%, dan pasien bisa kembali ke rumah. Tiga bulan setelah pembedahan, pasien datang ke poliklinik rawat jalan untuk evaluasi. Kondisi jari baik namun pergerakannya terbatas. Kemudian, pada pasien direncanakan untuk rekonstruksi jari pertama dengan transfer jari kedua jari kaki. Hasilnya, evaluasi jari pertama yang baru, dengan keadaan yang baik, dapat bergerak tetapi tidak dapat fleksi dan ekstensi penuh. Simpulan: pilihan rekonstruksi untuk mengembalikan fungsi jari pertama jari tangan termasuk transfer jari kedua jari kaki ke jari pertama jari tangan atau pollicization jari telunjuk. Jari kaki ke jari tangan untuk rekonstruksi jari pertama dapat memberikan hasil yang sangat baik dan tingkat kepuasan pasien yang tinggi.
\end{abstract}

Kata kunci: rekonstruksi jari pertama jari tangan, transfer jari kedua jari kaki.

\section{SECOND TOE TRANSFER FOR THUMB RECONSTRUCTION AFTER ELECTRICAL INJURY (CASE REPORT)}

\author{
Agus Roy R.H. Hamid ${ }^{1 *}$, Sitti Rizaliyana1, M. Sjaifuddin Noer', Gwendy Aniko² \\ ${ }^{1}$ Plastic and Reconstructive Surgery Training Programme, Faculty of Medicine Airlangga University, Dr. \\ Soetomo Hospital, Surabaya, Indonesia. *Correspondence: royruslyhamid@yahoo.com. \\ ${ }^{2}$ Department of Plastic and Reconstructive Surgery, Faculty of Medicine University of Indonesia, Dr. Cipto \\ Mangunkusumo Hospital, Jakarta, Indonesia.
}

\begin{abstract}
Background: the thumb plays an important role in hand function. Reconstruction of thumb iss done using the great toe. The second toe is used when the great toe is not acceptable as a donor site, for instance, when the level of amputation is through the proximal third of the first metacarpal and a significant length of metatarsal bone is necessary to provide adequate length in the reconstructed thumb. Case: reported one case, 24 year-old male, who came to Emergency Room of Dr. Soetomo Hospital with the absent of the right thumb after electrical injury. He had already done debridement and local flap on the left wrist and skin graft on the right wrist. Flap were viable and warm.Five days after surgery,
\end{abstract}


graft take was $100 \%$, thus he could be discharged. Three months after first surgery, he was admitted to outpatient clinic for evaluation. The thumb was good but the movement was limited. He was planned to undergo reconstruction of the thumb with second toe transfer. The new reconstructed thumba was viable, mobile, but with limited flexion and extension movement. Conclusion: reconstructive options to restore thumb function include a second toe-to-thumb transfer or pollicization of the index finger. Toe to hand transfer for thumb reconstruction can provide excellent end-result and a high degree of patient satisfaction.

Keywords: thumb reconstruction, second toe transfer.

\section{LATAR BELAKANG}

Indikasi untuk melakukan rekonstruksi pada jari pertama tangan dapat menggunakan jari pertama dan kedua jari kaki. Jari kedua jari kaki digunakan jika jari pertama jari kaki tidak sesuai dengan daerah donor, seperti permintaan pasien, di mana jari pertama jari kaki terlalu besar. ${ }^{1-3}$ Indikasi lainnya menggunakan jari kedua jari kaki kalau level dari amputasi jari pertama tangan setinggi sepertiga proksimal sampai tulang metacarpal sehingga didapatkan panjang jari pertama yang sesuai. Jari kedua jari kaki juga dapat digunakan untuk rekonstruksi jari pertama jari tangan dengan level amputasi setinggi sendi interpalang terutama pada anakanak. $^{1-9}$

\section{KASUS}

Melaporkan laki-laki, 29 tahun datang ke Unit Gawat Darurat RSUD Dr. Soetomo pada tanggal 10 Mei 2006 dengan keluhan lengan kanan dan kiri tersetrum listrik 1 bulan sebelum masuk rumah sakit. Sebelumnya, penderita dirawat di RS Mojowarno, Jombang dan telah dilakukan fasiotomi pada lengan kanan dan kiri.

Pada pemeriksaan fisik didapatkan keadaan umum dalam batas normal. Dan pemeriksaan status lokalis regio antebrachii sinistra dan manus sinistra, raw surface $1 \mathrm{x}$ $15 \mathrm{~cm}$ memanjang dari $1 / 3$ tengah lengan kiri sampai regio Hipotenar tangan kiri, terdapat jaringan nekrotik, dan tidak terdapat pus. Pada regio antebrachii dekstra, didapatkan raw surface 2 x $2 \mathrm{~cm}$, terdapat jaringan nekrotik, tidak terdapat pus, dan jaringan parut memanjang pada sisi anterior. Pada regio manus dekstra didapatkan thumb absent setinggi sendi metacarpophalang, tampak tulang dan tendon, jaringan granulasi, dan pus (gambar 1). Pasien didiagnosis dengan raw surface $2 \%$ regio ekstremitas superior dekstra et sinistra, bone exposed regio metacarpophalangeal joint digiti I manus dextra, dan tendon exposed regio wrist dextra ec electrical injury.

Dilakukan penanganan pada regio antebrachii sinistra, telah dilakukan debridemen dan flap lokal untuk menutup raw surface pada regio wrist dan skin graft untuk menutup defek sekunder. Pada regio antebrachii dekstra dilakukan debridemen dan flap lokal untuk menutup defek pada regio wrist dan skin graft untuk menutup defek sekunder (gambar 2).

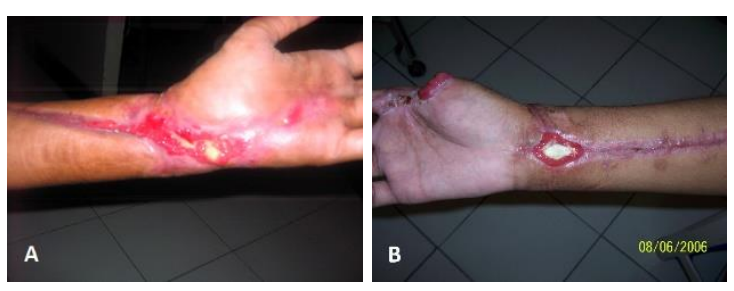

Gambar 1. Kondisi saat datang ke UGD, regio anterbrachii dan manus sinistra (A), regio antebrachii dan manus dekstra (B). 

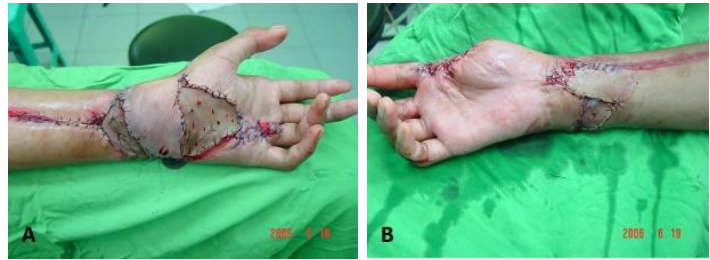

Gambar 2. Kondisi saat paska operasi, regio anterbrachii dan manus sinistra (A), regio antebrachii dan manus dekstra (B).

Tiga bulan paska operasi (gambar 3,4), penderita datang ke poli bedah plastik dan rekonstruksi RSUD Dr. Soetomo dengan keadaan umum baik, status lokalis regio antebrachii dan manus sinistra, terdapat scar, flap viable, dan graft take. Regio antebrachii dan manus dekstra, terdapat scar, flap viable, graft take, dan absent of the thumb. Masih didapatkan keterbatasan gerak pada regio wrist dekstra dan sinistra.

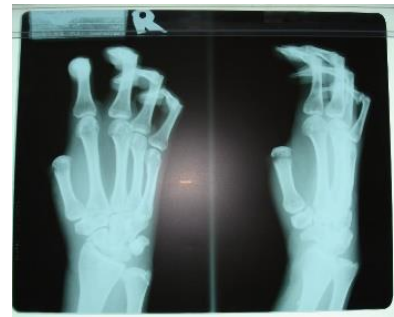

Gambar 3. Foto radiologi regio manus dekstra posisi anteroposterior (AP) dan oblik.

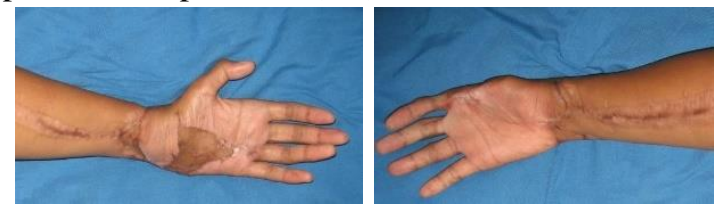

Gambar 4. Tiga bulan paska operasi, saat penderita datang ke poli bedah plastik dan rekonstruksi RSUD Dr. Soetomo.

\section{Penderita direncanakan untuk dilakukan thumb reconstruction dengan menggunakan second toe transfer pada regio manus dekstra (gambar 5-13).}

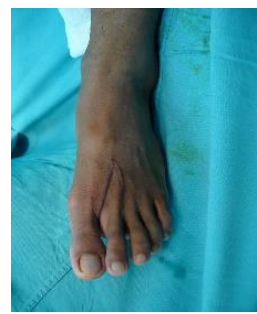

Gambar 5. Insisi kulit dibuat pada sisi dorsal.

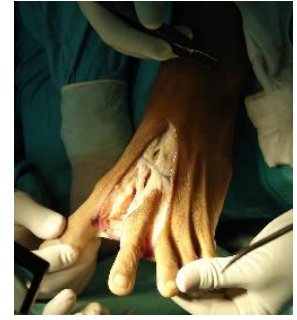

Gambar 6. Flap Triangular dibuat memanjang ke arah volar sehingga penutupan luka pada kaki akan lebih mudah. Tepat dibawah kulit, vena dorsalis tepat berada dibawahnya. Insisi kulit diteruskan ke proksimal tepat diatas pembuluh darah pedis bagian dorsal. Melalui insisi ini, vena superficialis dapat diikuti ke proksimal dan medial sehingga diketahui seberapa panjang pembuluh darah yang diperlukan untuk dilakukan anastomosis ke tangan.

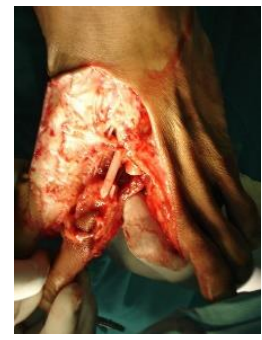

Gambar 7. Dilakukan identifikasi tendon ekstensor hallucis brevis dan berada dekat tendon ekstensor hallucis longus. Tepat dibawah tendon hallucis brevis, berjalan arteri dorsalis pedis dan vena comitantes. Pada level ini, arteri tepat berada pada tulang tarsal yaitu pada tulang cuneiformis pertama. Arteri melewati sisi distal pada proksimal webbing pertama, disebut arteri metatarsal sisi dorsal yang membentuk arkus dorsalis, dan melewati head dari otot interosseous sisi dorsal dan membentuk sirkulasi sisi plantar. Arteri metatarsal pertama sisi dorsal berjalan ke distal melewati fascia superficialis atau profunda pada otot interosseous pertama sisi dorsal. Biasanya, arteri terletak di bawah otot pada webbing pertama. Cabang dari arteri metatarsal pertama sisi dorsal yang menuju jari I diligasi, seperti pada gambar. Insisi dilanjutkan ke webbing I sampai ke sisi plantar dari kaki. Neurovascular bundle pada sisi lateral jari I diikuti ke arah proksimal sampai didapatkan neurovascular bundle dari jari II. Nervus digitalis pada webbing I harus dipisahkan untuk mengetahui panjang nervus digitalis yang diperlukan. Arteri jari I sisi plantar pedis kiri diligasi dan arteri utama dipisahkan ke arah proksimal sampai didapatkan panjang arteri yang diperlukan. Ligamen transversal metatarsal I diinsisi untuk membebaskan kepala metatarsal II ke arah medial sehingga dapat dilakukan deseksi ke arah proksimal. 

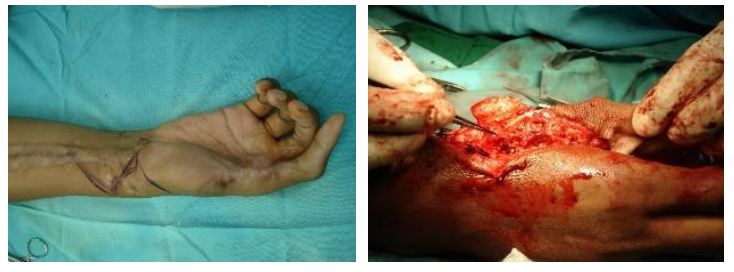

Gambar 8. Insisi zigzag pada regio wrist sisi radial manus dekstra, preservasi arteri interdigitalis cabang dari arteri radialis. Setelah terjadi reperfusi, pembuluh darah diligasi dan tendon ekstensor dipotong dan jari kaki siap ditransfer ke tangan. Tampak tendon ekstensor dan fleksor setelah dipotong dan arteri dorsalis pedis yang menuju jari kedua ditelusuri serta cabang-cabang arteri diligasi serta cabang arteri ke great toe juga dilakukan ligasi. Tampak kelompok neurovaskular pada sisi plantar.

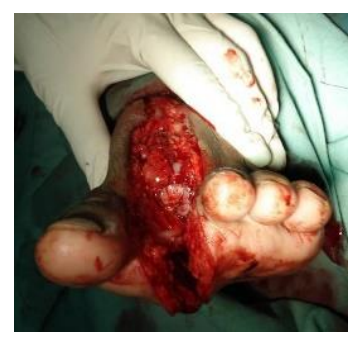

Gambar 9. Setelah ligament metatarsal dipotong untuk memudahkan dilakukan penutupan luka operasi.
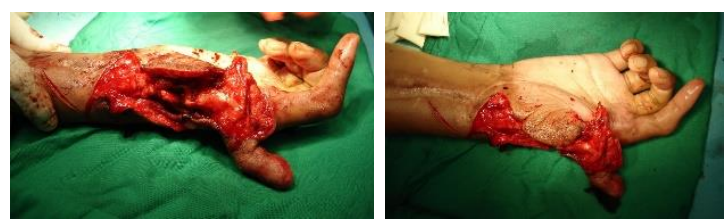

Gambar 10. New thumb setelah dilakukan anastomosis dan raw surface ditutup dengan skin graft.
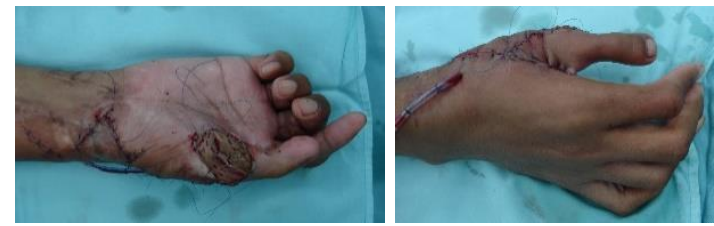

Gambar 11. Hasil paska operasi.
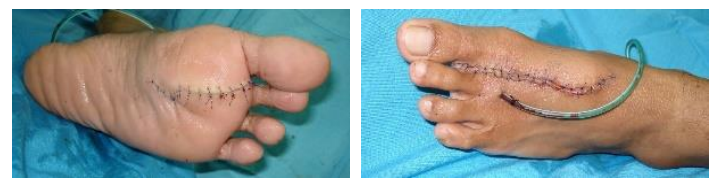

Gambar 12. Luka pada donor site.
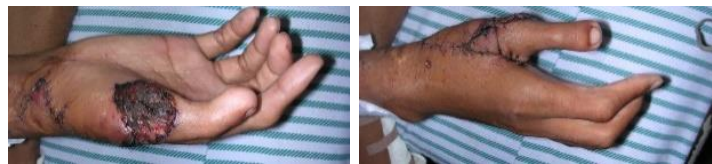

Gambar 13. Lima hari setelah operasi, graft take $100 \%$, ujung distal viable, kemerahan, dan capillary refill kurang dari 2 detik.

Operasi rekonstruksi jari pertama jari tangan dengan menggunakan transfer jari kedua jari kaki pertama kali dilakukan oleh bagian bedah plastik dan rekonstruksi FK Unair/RSUD Dr. Soetomo. Teknik operasi ini tingkat kesulitannya cukup tinggi dengan kemungkinan komplikasi yang besar.

Pada kasus diatas, setelah dilakukan rekonstruksi jari pertama jari tangan pada penderita dengan thumb loss setelah tersetrum listrik, hasilnya cukup baik dengan evaluasi ujung distal viable, kemerahan, dan hasil evaluasi graft take $100 \%$. Satu minggu setelah dilakukan operasi rekonstruksi jari pertama jari tangan, penderita pulang, dan sangat puas dengan hasil operasi ini.

\section{DISKUSI}

Hasil fungsional dari transplantasi kaki ke tangan tidak dapat diatasi dengan metode rekonstruktif konvensional lainnya. Tingkat kelangsungan hidup dalam rangkaian besar 400 kasus adalah 96,5\%. ${ }^{10}$ Eksplorasi ulang perlu diperlukan dalam kira-kira $10 \%$ kasus. Prosedur sekunder biasanya dilakukan, sebagian besar berbentuk pulp-plasties atau tenolyses kecil.

Jari kaki relatif tidak bergerak sehingga rentang gerak yang normal tidak mungkin terjadi, meskipun busur fungsional harus diharapkan. Pemulihan sensori pada umumnya baik jika dibandingkan dengan sensibilitas jari kaki dibandingkan dengan jari tangan normal. Kebanyakan pasien 
menganggap jari kaki yang ditransplantasikan sebagai jari dalam waktu 6 bulan setelah operasi. Pengamatan ini konsisten dengan studi MRI fungsional yang menunjukkan bahwa tugas motorik dan sensorik yang melibatkan kaki yang ditransplantasikan meningkatkan aktivasi dan rekrutmen kortikal di area tangan korteks sensorimotor primer. Hal ini mungkin juga terkait dengan pengamatan bahwa fenomena jari phantom sering timbul setelah transfer jari kaki. ${ }^{12-16}$

Di Rumah Sakit Chang Gung Memorial, Michigan Hand Outcomes Questionnaire (MHQ) telah digunakan untuk menilai hasil di antara sekelompok pasien yang menjalani transfer amputasi jari kaki dibandingkan dengan kelompok yang memiliki luka serupa yang tidak menjalani rekonstruksi. Nilai MHQ dari kelompok transfer jari kaki lebih dari 50\% lebih tinggi daripada kelompok non-rekonstruksi untuk keseluruhan fungsi, aktivitas kehidupan sehari-hari (ADLs), dan kepuasan serta hampir $100 \%$ lebih tinggi untuk hasil estetika. Melihat hanya pada studi kohort yang menjalani transfer dan membandingkan tangan yang direkonstruksi dengan tangan kontralateral yang tidak terluka, skor MHQ adalah 93\% normal untuk keseluruhan fungsi dan ADLs, dan $80 \%$ normal untuk estetika dan kepuasan. Jadi, meski gerak dan sensasi normal tidak boleh diantisipasi, operasi transfer jari kaki bisa mengembalikan fungsi dan penampilan mendekati level normal. ${ }^{12-16}$

\section{SIMPULAN}

Operasi rekonstruksi pada jari pertama jari tangan dengan menggunakan jari kedua jari kaki, hasilnya cukup memuaskan, karena selain mendapatkan panjang jari pertama yang diganti, juga dari bentukan anatomi kebanyakan lebih mirip dengan jari pertama. Demikian juga dilihat dari level amputasi pada pasien diatas, sehingga indikasi operasi rekonstruksi pada jari pertama jari tangan dengan menggunakan jari kedua jari kaki sudah sesuai dengan indikasi.

\section{DAFTAR PUSTAKA}

1. Buncke HJ. Microsurgery: Transplantation and Replantation. Philadelphia: Lea \& Febiger; 2002.

2. Bueno RA. Thumb Reconstruction. (serial online) 2006. [cited 2006 August 13]. Available from: https://emedicine.medscape.com/article /1244563-overview.

3. Wilhelmi BJ. Digital Amputation. (serial online) 2006. [cited 2006 November 12]. Available from: https://emedicine.medscape.com/article /1238395-overview.

4. Tsai TM, D'Agostino L, Fang YS, et al. Compund flap from the great toe and vascularized joints from the second toe for posttraumatic thumb reconstruction at the level of the proximal metacarpal bone. Microsurger. 2009;29:178-83.

5. Pan YW, Zhang L, Tian W, et al. Donor foot morbidity following modified wraparound flap for thumb reconstruction : a follow-up 69 cases. $J$ Hand Surg Am. 2011;36:493-501.

6. Wallace CG, Wei FC. Posttraumatic finger reconstruction with microsurgcial transplantation of toes. Hand Clin. 2007;23:117-28.

7. Lee DC, Kim JS, Ki SH, et al. Partial second toe pulp free flap for fingertip reconstruction. Plast Reconstr Surg. 2008;121:899-907.

8. Cheng G, Feng G, Hou S, et al. Aesthetic reconstruction of thumb or finger partial defect with trimmed toe- 
flap transfer. Microsurgery. 2007;27:74-83.

9. Woo SH, Lee GJ, Kim $\mathrm{KC}$, et al. Cosmetic reconstruction of distal finger absence with partial second toe transfer. $J$ Plast Reconstr Aesthet Surg. 2006;59:317-24.

10. Jones NF, Hansen SL, Bates SJ. Toe-tohand transfers for congenital anomalies of the hand. Hand Clin. 2007;23:12936.

11. Gu YD, Cheng DS, Zhang GM, et al. Long- term results of toe transfer: retrospective analysis. $J$ Reconstr Microsurg. 1997;13:405-8.

12. Frykman GK, O'Brien BM, Morrison WA, et al. Functional evaluation of the hand and foot after one-stage toe-tohand transfer. $J$ Hand Surg Am. 1986;11:9-17.

13. Wei FC, Carver N, Lee YS, et al. Sensory recovery and Meissner corpuscle number after toe-to-hand transplantation. Plast Reconstr Surg. 2000;105:2405-11.

14. Lin CH, Lin YT, Sassu P, et al. Functional assessment of the reconstructed fingertips after free toe pulp transfer. Plast Reconstr Surg. 2007;120:1315-1321.

15. Chu NS, Wei FC. Recovery of sensation and somatosensory evoked potentials following toe-to-digit transplantation in man. Muscle Nerve. 1995;18:859-66.

16. Chung K, Wei FC. An outcome study of thumb reconstruction using microvascular toe transfer. J Hand Surg Am. 2000;25:651-8. 